\title{
What causes subsidence following the 2011 eruption at Nabro (Eritrea)?
}

\author{
Joanna Hamlyn ${ }^{1}$, Tim Wright ${ }^{*}$ (1), Richard Walters ${ }^{3}$, Carolina Pagli4, Eugenio Sansosti ${ }^{5}$, Francesco Casu ${ }^{5}$, \\ Susi Pepe ${ }^{5}$, Marie Edmonds 6 , Brendan McCormick Kilbride ${ }^{6}$, Derek Keir ${ }^{7,8}$, Jürgen Neuberg ${ }^{2}$ \\ and Clive Oppenheimer ${ }^{9}$
}

\begin{abstract}
A major goal in volcanology is to be able to constrain the physical properties of a volcanic system using surface observations. The behaviour of a volcanic system following an eruption can provide powerful constraints on these properties and can provide valuable information for understanding future hazard. We use spatially and temporally dense observations of surface deformation following the 12 June 2011 eruption of Nabro (Eritrea) to place constraints on the mechanics of its subsurface volcanic system. Nabro was imaged 129 times by TerraSAR-X and COSMO-SkyMed satellites during a 15-month period following the eruption. We have produced a detailed time series of the line-of-sight (LOS) displacements at Nabro, finding that the volcano subsides during the entire observation period at a decaying rate. We found significant atmospheric artefacts remained in the data set after a standard spatio-temporal filter was applied. Applying an empirical correction using a linear phase-elevation relationship removed artefacts but also removed real topographically correlated deformation. Instead, we were able to correct each SAR acquisition using independent delay estimates derived from the ECMWF ERA-Interim (ERA-I) global atmospheric model. The corrected time series can be modelled with the deflation of a Mogi source at $\sim 6.4 \pm 0.3 \mathrm{~km}$ depth. Modelling the time series using viscoelastic relaxation of a shell which surrounds a spherical magma chamber can explain the observed subsidence without a source of further volume loss if the magma is compressible. $\mathrm{CO}_{2}$ outgassing is also a possible cause of continued subsidence. Contraction due to cooling and crystallisation, however, is probably minor. If any post-eruptive recharge of the magmatic system at Nabro is occurring, the rate of recharge must be slower than the post-eruptive relaxation processes. Combined with the lack of pre-eruptive inflation, we suggest that recharge of the magmatic system at Nabro either occurs at a rate that is slower than our detection limit, or it occurs episodically. This case study demonstrates the power of long, dense geodetic time series at volcanoes.
\end{abstract}

Keywords: InSAR, Time series, Atmospheric Correction, Subsidence, Viscoelastic modelling, Outgassing

\section{Introduction}

The pattern and rate of surface deformation observed after a volcanic eruption are dependent on the magmatic processes occurring at depth and the rheology of the crust and magma. Detailed surface observations from satellite radar interferometry (InSAR; Zebker et al. 1997; Massonnet and Feigl 1998; Burgmann et al. 2000; Hooper et al. 2012) may allow us to constrain these properties. Simple models can be used to assess the relative importance of different

\footnotetext{
${ }^{*}$ Correspondence: t.j.wright@leeds.ac.uk

${ }^{2}$ COMET, School of Earth and Environment, University of Leeds, Leeds LS2 9JT, UK

Full list of author information is available at the end of the article
}

mechanisms occurring in the magmatic system following eruption, including magma recharge (e.g. Lu et al. 2010), cooling and crystallisation (e.g. Parker et al. 2014), degassing (e.g. Girona et al. 2014) and viscoelastic relaxation (e.g. Parks et al. 2015 and Segall 2016).

Following an eruption, there are numerous processes which may control whether a volcanic edifice undergoes a period of uplift, subsidence or remains at a given height. Edifice uplift due to post-eruptive recharge of a magma chamber has been observed at many volcanoes, including Alu-Dalafilla (Ethiopia) following the 2008 eruption (Pagli et al. 2012) and Gabho and Dabbahu (Ethiopia) following the 2005 Dabbahu-Manda-Hararo rifting episode (Wright et al. 2006; Grandin et al. 2010). In contrast,

\section{Springer Open}

(c) The Author(s). 2018 Open Access This article is distributed under the terms of the Creative Commons Attribution 4.0 International License (http://creativecommons.org/licenses/by/4.0/), which permits unrestricted use, distribution, and reproduction in any medium, provided you give appropriate credit to the original author(s) and the source, provide a link to the Creative Commons license, and indicate if changes were made. 
some volcanoes show long-lived subsidence following an eruption. Lliama volcano (Chile) subsided over 3.5 years following an eruption in 2003 (Girona et al. 2014), which was attributed to post-eruptive outgassing (Bathke et al. 2011). Some post-eruption magmatic processes do not result in geodetic signals at the surface. The time series of ground displacement at Okmok volcano (Alaska) between the 1997 and 2008 eruptions showed periods of inflation due to magma supply and periods of deflation due to degassing (Lu et al. 2010). If the inflation and deflation processes are balanced and contemporaneous, no ground deformation will result (Lu et al. 2010). Magma migration at depth might not result in a geodetic signal with a magnitude greater than the noise, effectively becoming invisible to current geodetic instruments (Pagli et al. 2012), if the magma is deep, highly compressible or if small volumes of magma are moving. Alternatively, the process could be overlooked if the temporal resolution of the geodetic data is too low (e.g. Chaitén, Chile (Fournier et al. 2010)).

InSAR is well-suited to monitoring ground deformation on the scale of individual volcanoes to entire volcanic arcs. However, careful consideration needs to be given to spatio-temporal variation of atmospheric refractivity between image acquisitions, which causes artefacts within the InSAR signal (e.g. Beuducel et al. 2000). In tropical regions, atmospheric conditions can create significant spurious ground movement (e.g. Ebmeier et al. 2013). Although our study region Afar (Eritrea/Ethiopia) is more arid than most of the tropics, here, we show the importance of applying atmospheric corrections despite the arid environment. We also show the importance of using external, independent data to preserve topographically and temporally correlated deformation.

Nabro volcano (Fig. 1) erupted on 12 June 2011 with co-eruptive activity extending into July 2011 (Goitom et al. 2015). A detailed synthesis of the eruption can be found in Goitom et al. (2015). A $17.5 \mathrm{~km}$ long lava flow was emplaced to the SW of the edifice, and $4.3 \mathrm{Tg}$ of $\mathrm{SO}_{2}$ was emitted into the atmosphere (Theys et al. 2013), one of the largest atmospheric aerosol perturbations since Mt. Pinatubo emitted approximately $20 \mathrm{Tg}$ of $\mathrm{SO}_{2}$ to the atmosphere during the 1991 eruption (Bluth et al. 1992). Hamlyn et al. (2014) previously found that the magma chamber which fed the eruption is centred under the SW caldera rim and can be adequately modelled by a Mogi solution at a depth of $\sim 7 \mathrm{~km}$. There is no indication that a magmatic link exists between Nabro and neighbouring Mallahle volcano. However, changes to the local stress regime following the eruption induced seismicity beneath Mallahle (Hamlyn et al. 2014).

In this paper, we measure the time-dependent subsidence of Nabro volcano following the June to July 2011 eruption using SAR images acquired by COSMO-SkyMed (CSK) and TerraSAR-X (TSX) satellites. We find that despite the arid environment, the InSAR-derived time series contain significant atmospheric artefacts, and so, we attempt to mitigate these effects trying both empirical and weather model corrections. Finally, we assess the relative contributions of potential mechanisms that may control the observed time-dependent subsidence.

\section{Methods \\ InSAR Data and corrections Interferograms}

We processed a COSMO-SkyMed (CSK) data set that is composed of 64 SAR images acquired on a descending track between 26 June 2011 and 18 July 2012. During this time period, the CSK satellites were positioned in nonsymmetric configuration; in a 16-day cycle, there are four interferometric acquisitions (on day 1, day 9, day 10 and day 13). The CSK SAR sensors operate in the X-band, emitting a radar pulse with a $\sim 31 \mathrm{~mm}$ wavelength (Covello et al. 2010). The sensor was used in StripMap mode (HIMAGE) to observe Nabro, with a swath $40 \mathrm{~km}$ wide and a spatial resolution of about $3 \mathrm{~m}$. After multilooking to improve the signal to noise ratio, the final spatial resolution is $\sim 30 \mathrm{~m}$ in both the azimuth and ground range directions. In total, we produced 171 small baseline interferograms with a maximum perpendicular baseline of $360 \mathrm{~m}$ and temporal baseline between 3 and 323 days.

The TerraSAR-X (TSX) satellite acquired images on both ascending and descending passes over the Nabro region. The TSX SAR sensors also operate in the X-band. We obtained 36 images in StripMap mode between 1 July 2011 and 5 October 2012 on descending orbit 046 and 27 images spanning the period between 6 July 2011 and the 10 October 2012 on ascending orbit 130. Both covered regions $30 \mathrm{~km}$ wide in range and $50 \mathrm{~km}$ long in azimuth. Using ROI_PAC software (Rosen et al. 2004), we created connected networks of 67 small baseline interferograms from the descending data set and 44 interferograms from the ascending data set (example interferograms are shown in Fig. 2). The interferograms used have a maximum perpendicular baseline of $200 \mathrm{~m}$ and temporal baseline between 11 and 390 days. We used the interferograms in which we were able to unwrap at least $90 \%$ of the image, reducing the data set to 34 interferograms from the descending track and 21 interferograms from the ascending track.

\section{Ratemaps and initial time series}

We created a time series of the ground displacement from the CSK and TSX data sets using small baseline subset (SBAS) techniques (Berardino et al. 2002). The CSK data is highly coherent; there are approximately 3.5 million pixels in the ratemap (a map of average velocity; Fig. 3). During processing, we removed long wavelength phase trends in the velocity maps using a planar fit. 


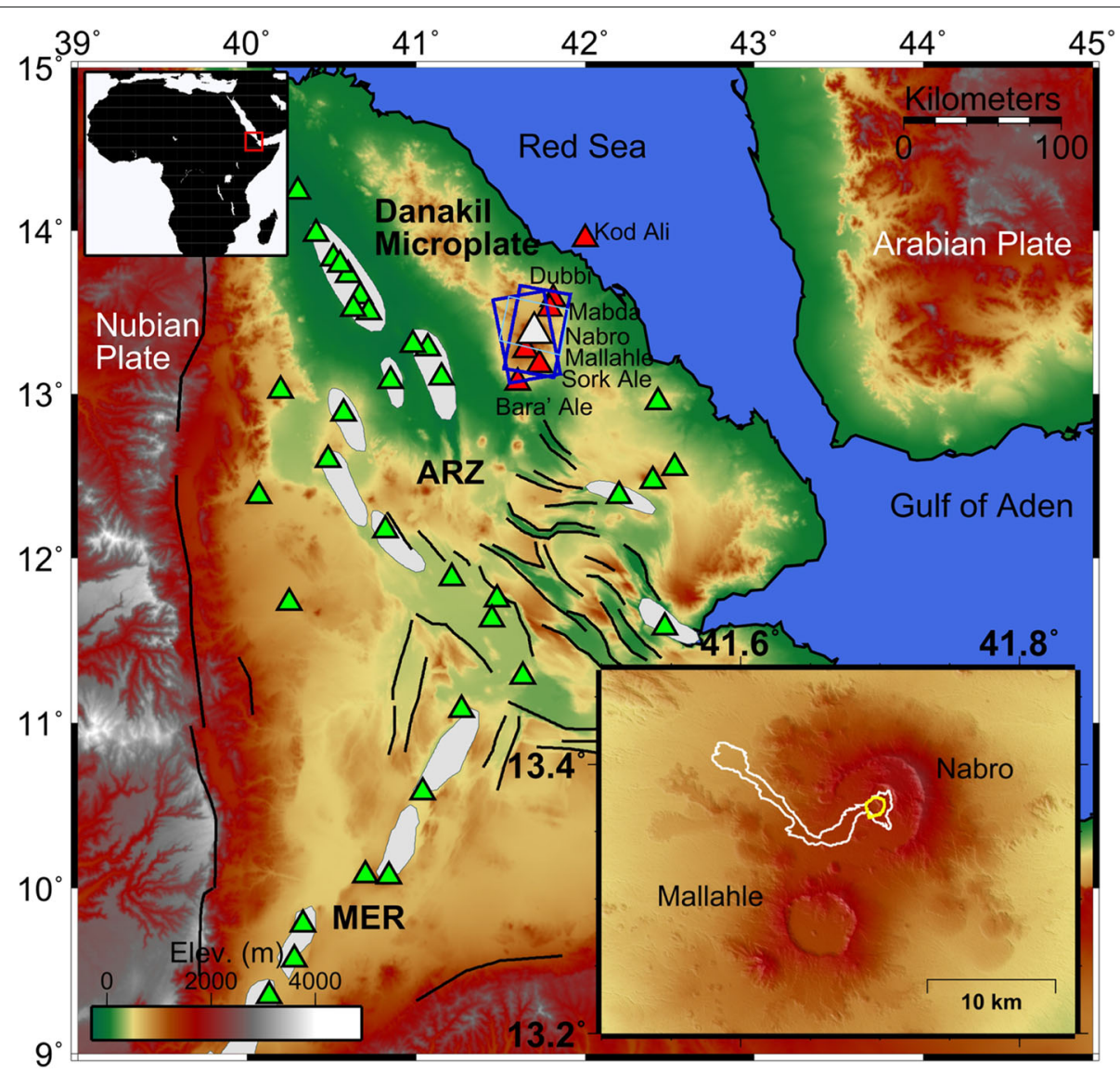

Fig. 1 Topographic map of the Afar Rift Zone (ARZ) from the $90 \mathrm{~m}$ SRTM elevation model. Black lines show the regional faults; grey shading shows volcanic segments. Green triangles show positions of volcanoes in the region as defined by the Smithsonian catalogue; red triangles show the volcanoes that comprise the NVR with Nabro highlighted as a white triangle. The footprint of the CSK acquired SAR images is shown in light blue and TSX footprints in dark blue. Upper left inset: the position of the Afar Rift Zone and Main Ethiopian Rift (MER) on the African continent. Lower right inset: topographic map of Nabro and Mallahle volcanoes. The lava flow produced by the 2011 eruption is outlined in white, and the main vent region is outlined in yellow

The CSK data was processed at the Italian National Research Council-Istituto per il Rilevamento Elettromagnetico dell'Ambiente (CNR-IREA) using their internally developed interferometric SAR processing chain to apply the SBAS technique (Berardino et al., 2002). The SBAS technique was applied to the TSX data set using $\pi$-RATE software (Wang et al. 2009; Biggs et al. 2007; Elliott et al. 2008). A standard (Wang et al. 2009) spatio-temporal filter was initially applied to the data sets to remove atmospheric artefacts, with a temporal averaging window of 70 and 73 days for the CSK and TSX data, respectively.

In the maps of average velocity (ratemaps) for the CSK and TSX (both ascending and descending) data sets, we observe a nearly circular, $12 \mathrm{~km}$ wide increase in the lineof-sight (LOS) direction. The mean look angles for the TSX ascending and descending data are quite similar, with values of $27.8^{\circ}$ and $33.3^{\circ}$, respectively, while CSK data are acquired with a mean look angle of $21.8^{\circ}$; the positive LOS velocities (away from the satellite) around the volcano suggests a predominance of vertical deformation with a non-negligible horizontal component, consistent with the joint inversion of the TSX ratemaps for a Mogi source in Hamlyn et al. (2014).

\section{Atmospheric corrections}

Temporal variations in atmospheric conditions, and in tropospheric water vapour in particular, are known to contaminate InSAR time series (e.g. Zebker et al. 1997; Bekaert et al. 2015). A standard method to correct for these is to use spatial and temporal filtering to isolate and remove the atmospheric delay; the delay fields (atmospheric phase screens or APS) are assumed to be random in time but correlated in space (Ferretti et al. 2001). Applying this method to the dense time series of the summit relative to a reference pixel from CSK data produces steady, smooth time series of increased LOS displacement (subsidence) over Nabro volcano (Fig. 4) that are punctuated by two apparent periods of decreased LOS displacement 


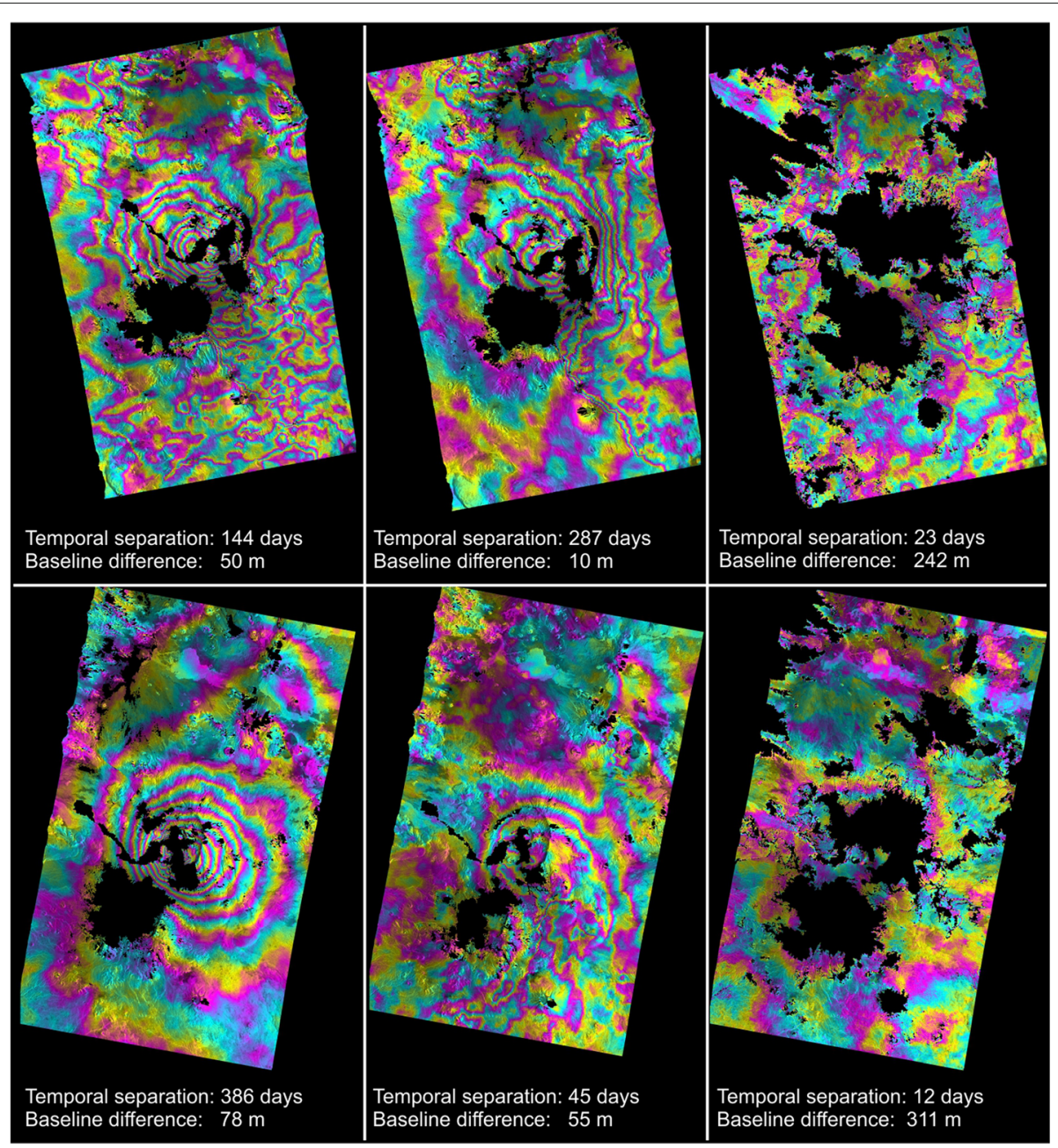

Fig. 2 Interferograms from the TSX satellite showing the coherence over different temporal separations and spatial baselines. The interferograms are wrapped at $2 \pi$. Interferograms with baselines larger than $200 \mathrm{~m}$ with less than $90 \%$ unwrappable pixels were not used in this study

(uplift, indicated by grey bars in Fig. 4a) in November 2011 and April 2012. If these pulses are real, they have important ramifications for modelling and interpretation of magmatic processes within Nabro's plumbing system, implying that the system is becoming re-pressurised due to short periods of magmatic recharge. After similar time series filtering, these reversals were not present in the TSX data sets, which have lower temporal resolution. To investigate whether these apparent reversals in LOS displacement are real or not, we tested alternative atmospheric corrections on our CSK data.

An alternative method for correction of atmospheric signals, which is commonly and routinely applied in InSAR analysis, is to remove the component of the tropospheric delay that is correlated with topography (Wicks et al. 2002; Elliott et al. 2008; Bekaert et al. 2015). To apply this correction, we estimate a linear relationship between LOS displacement and elevation and subtract this from each epoch in the time series. We applied this method on the CSK time series and found that the corrected time series is smoother in time (Fig. $4 \mathrm{~d}$, green dots), showing steady subsidence over the observation period. Importantly, the two periods of apparent reversal in the subsidence trend have been suppressed, suggesting that these could be the result of topographically correlated atmosphere. However, the overall magnitude of the subsidence rate appears to have also been systematically reduced, with an apparent total range increase of $\sim 18 \mathrm{~cm}$ compared to $\sim 30 \mathrm{~cm}$ for the uncorrected time series. This is likely because deformation is also correlated with topography, and hence, this correction method applied in its simplest form is removing the real volcanic subsidence signal as well as the topographically correlated atmospheric signal.

To avoid the issues with the two empirical atmospheric correction methods described above, we also attempted 


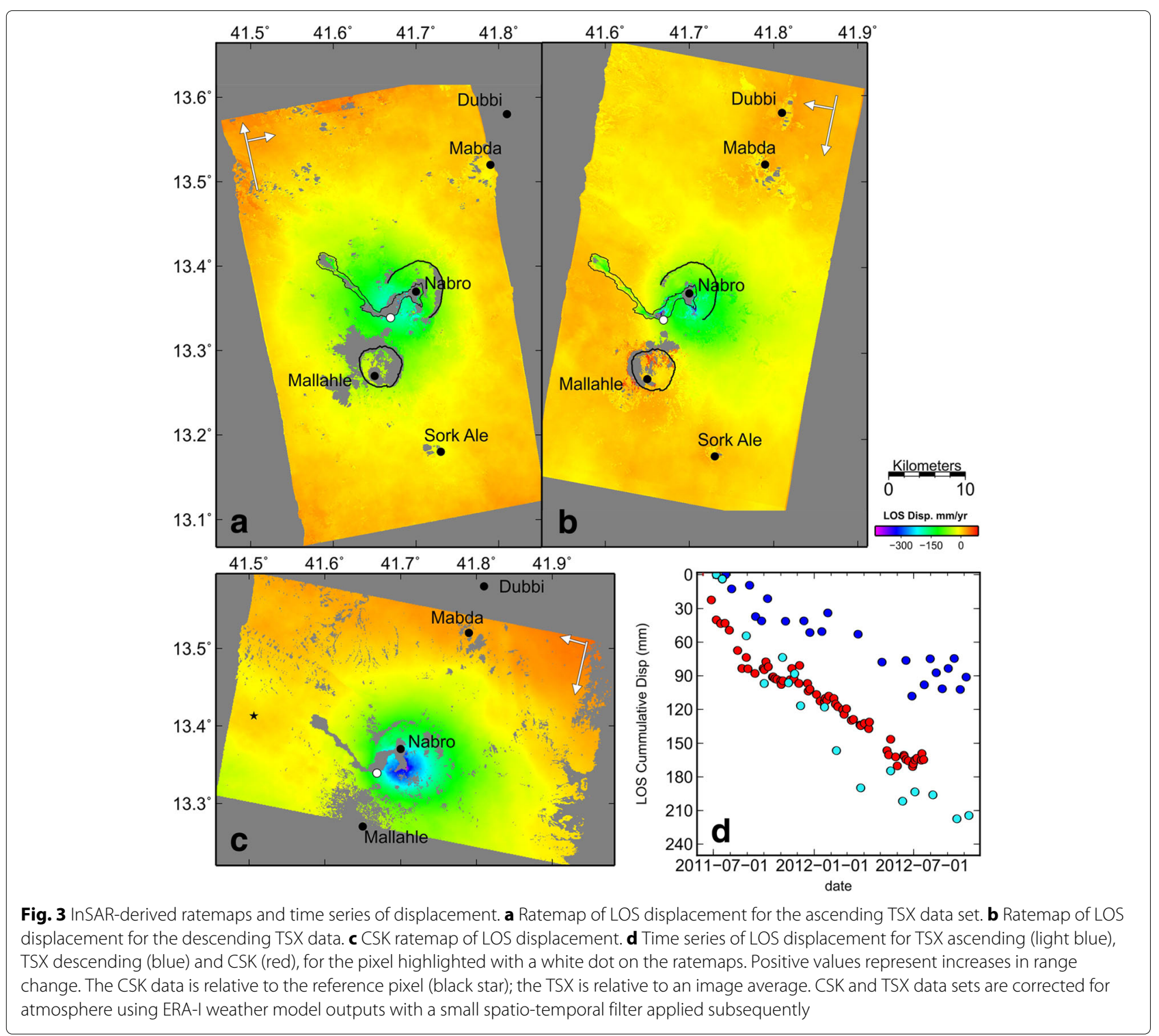

an alternative atmospheric correction using an independent data set estimates of atmospheric delay from the ERA-Interim (ERA-I) weather model produced by the European Centre for Medium-range Weather Forecasting (ECMWF; Dee et al. 2011).

The ERA-I model provides estimates of atmospheric parameters daily at 00:00, 06:00, 12:00 and 18:00 UTC for grid nodes with $\sim 80 \mathrm{~km}$ horizontal spacing and at 37 vertical levels defined by their atmospheric pressure (Dee et al. 2011). Following the method described by Jolivet et al. (2011) and Walters et al. (2013), we model the estimates of temperature, relative humidity and geopotential height. For the model output times immediately preceding and following the SAR acquisition time, we interpolate values of these parameters between each pressure level and then calculate the atmospheric delay as a function of elevation. We use a bilinear interpolation between horizontally separated node points and a spline interpolation between nodes at different altitudes to calculate a 3D volume of predicted delay. A $90 \mathrm{~m}$ DEM acquired from the Shuttle Radar Topography Mission (SRTM) is used to select delay values at the ground surface, and therefore, the resulting phase maps have the same resolution as this DEM. Finally, we take our two correction maps calculated for our nearest model output times before and after the SAR acquisition and linearly interpolate to the time of acquisition. We calculate the wet and hydrostatic phase delay fields separately and add them together to give the total delay (full technical details are provided in Walters et al. (2013)). The hydrostatic delay has a large absolute value but has a much smaller temporal variation than the wet delay; the spatial variation of the wet delay on a given 

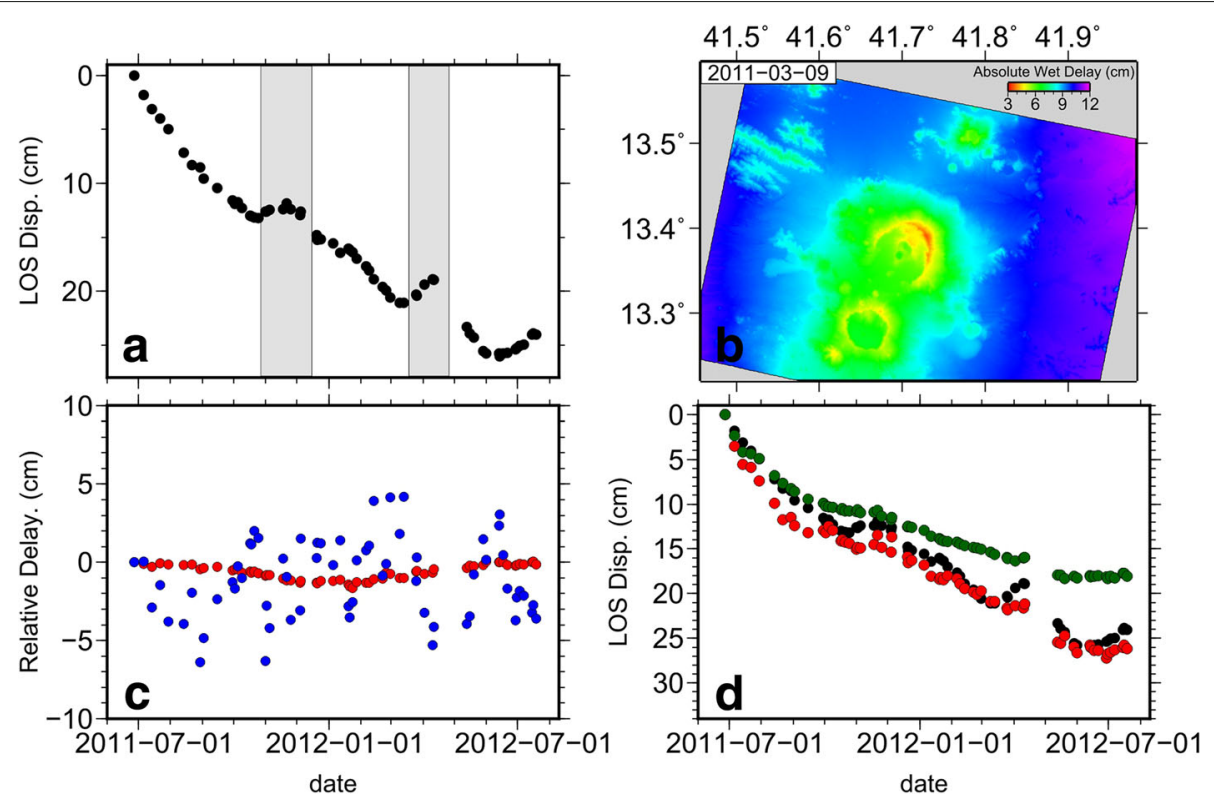

Fig. 4 a Filtered time series of range change (for pixel highlighted in white in Fig. 3c) for the CSK satellite corrected for atmosphere using a standard APS approach (spatio-temporal filtering). Grey bars indicate period of reversed LOS. b Example of observed absolute wet delay across Nabro caldera on a given date. c Time series of wet (blue) and hydrostatic (red) delays of the summit pixel with respect to the reference pixel (black star Fig. 2c), relative to the first day of acquisition. $\mathbf{d}$ Time series of range increase corrected using ERA-I data (red), APS spatio-temporal filtering (black) and a linear-with-height relationship (green)

date is shown in Fig. 4b. We have shown the time series of the hydrostatic and the wet delays at a summit pixel with respect to the delays at the reference pixel, relative to the first date of acquisition (Fig. 4c).

We applied the corrections to the 64 CSK epochs and then subsequently applied a spatio-temporal filter $($ of $1 \mathrm{~km}$ width and 10 day time window) to remove high-frequency temporal noise. The ERA-I-corrected and filtered CSK data (Figs. 3 and 4d, red dots) show no significant periods of reversed motion, and the magnitude of the total displacement rate is similar to the original raw time series. Although the corrected time series appears slightly noisier than the time series produced with spatio-temporal filtering or with a linear height correction, the use of weather model outputs allows for unbiased recovery of deformation signals, even when atmospheric delays are correlated in time or when the deformation and atmosphere are both correlated with topography. We therefore chose to apply the ERA-I filter with a subsequent spatio-temporal filter of 10 days to both the CSK and TSX data sets and to use these results when interpreting and modelling the deformation signals.

The TSX ratemaps that result from ERA-I-derived atmospheric corrections are more coherent and show a larger magnitude signal than those presented in Hamlyn et al. (2014), which were derived using an APS filter. The increased ERA-I coherence is because the APS model in $\pi$-RATE requires a linear rate of ground displacement. Pixels with a non-linear rate of displacement are removed, and this can lead to the removal of many pixels depending on threshold values.

\section{Corrected InSAR data}

The overall final data, corrected for atmospheric artefacts, are shown in Fig. 3. The same summit location and reference pixel were used in each time series. Both ascending- and descending-track TSX time series show a LOS displacement rate which is faster in the initial 2 months following the eruption than during the latter part of the time series. The overall gradient of LOS displacement then decreases for 12 months for the remainder of the observation period. Similar behaviour characterises the CSK time series. After the correction for atmospheric artefacts, the reversals in the deformation trend are significantly suppressed. The deformation trend is larger in the first few months following the eruptions and tends to rapidly decrease. The displacement time series shown are consistent with an exponential decay, although with different amplitudes in each data set; differences are due to the different look angles. Spatially, the deformation decreases in amplitude with distance from the top caldera. Temporal modelling of such a complicated signal is achievable when dealing with a few physical parameters derived from source modelling at different times, as shown in the next section. 


\section{Results}

\section{Kinematic modelling}

Previously, Hamlyn et al. (2014) found that a reduction in volume (pressure) at a point source (Mogi 1958) located $7 \pm 1 \mathrm{~km}$ beneath Nabro provided a good fit to the spatial deformation pattern and the linear deformation rate derived from ascending and descending TSX interferograms used in this study. In this section, we investigate whether the parameters describing this simple model are constant or change with time. The resultant model uses TSX and CSK data sets to constrain the changing source volume beneath Nabro at a high temporal resolution.

We first performed the inversions to find the location and cumulative volume change for a Mogi source for each acquisition date of the TSX and CSK time series independently. To determine the parameter errors for the non-linear inversions, we performed a Monte Carlo error analysis, first perturbing our data with realistic correlated noise, and then inverting these perturbed data sets using the same method as Parsons et al. (2006). We found that the surface position and depth of the source do not show any clear time-dependent trends, indicating that the location of the source is not moving significantly over time (Fig. 5). Therefore, as the source geometry appears stable, we can investigate the time-dependent volume change of the source by fixing the geometry (Lu et al. 2010; Pagli et al. 2012). We used the average values for each location parameter and solved only for the volume change as a function of time (Fig. 6). We checked the suitability of the Mogi solution for each pick by calculating the RMS difference between the model and the results of the Monte Carlo simulation for each epoch (Additional file 1: Figure S1). Because the initial acquisitions in each time series are on different dates, we needed to adjust the starting position of the TSX-derived time series of volume so that they were consistent with the CSK time series of volume. To do this, we calculated the linear displacement rate between the first and second CSK acquisition dates and offset the TSX data accordingly, as in Pagli et al. (2012).

When all other parameters are fixed, the three time series derived from different viewing geometries all show consistent change in cumulative source volume (Fig. 6). The results show an apparent rapid decrease of $0.013 \mathrm{~km}^{3}$ between 27 June 2011 and 10 July 2011 (dashed line, Fig. 6). During this time, the lava erupted from several locations within the caldera (Goitom et al. 2015). Therefore, we suggest that within this period, the volcano was still in a co-eruption phase. After the initial rapid subsidence associated with the end of the eruption, the apparent source volume then decreases steadily from an initial reduction of $\sim 0.013$ to $\sim 0.055 \mathrm{~km}^{3}$ over a period of 11 months, reaching $\sim 0.065 \mathrm{~km}^{3}$ after 15 months. The rate of volume decrease slows steadily throughout

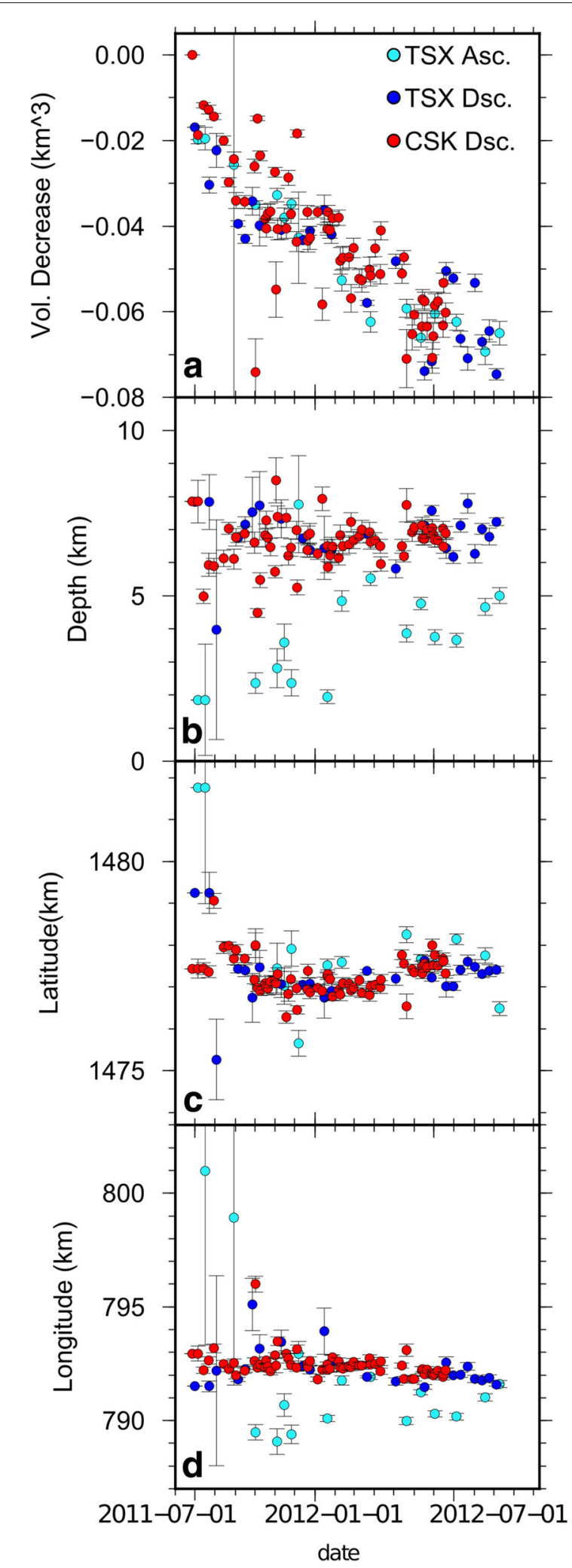

Fig. 5 Time series of inverted source geometry parameters; uncertainties in the model parameters for each date are found by using a Monte Carlo analysis. a Volume change. b Depth. c Latitude. d Longitude 


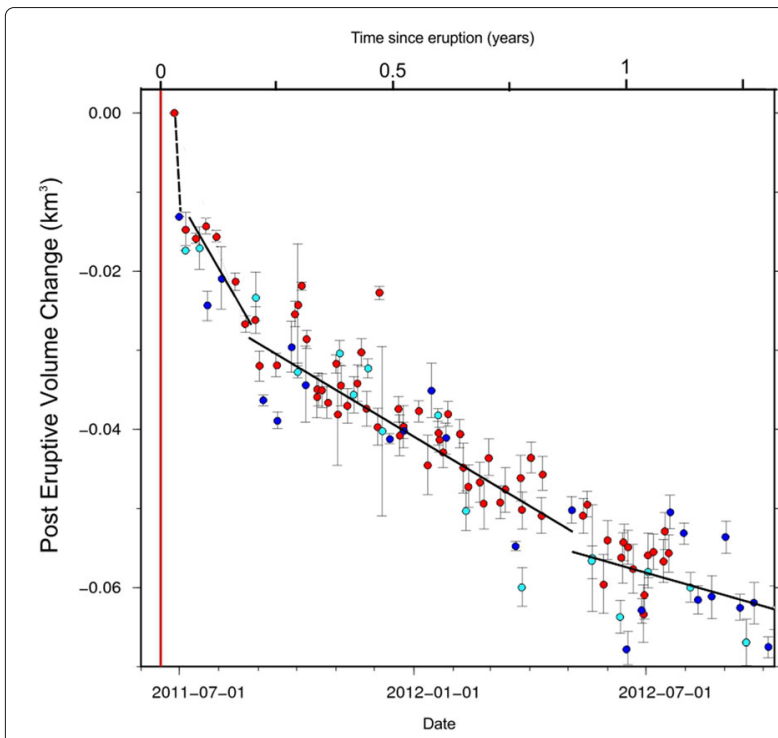

Fig. 6 Time series of volume change. Time is given in date (bottom) and years since the eruption started (top). The beginning of the eruption is indicated by the red line. Assuming a fixed geometry, a Mogi source at a depth of $6.4 \mathrm{~km}$ at $41.69^{\circ}$ (long) $13.36^{\circ}$ (lat). Black lines indicate the best-fit displacement rates, highlighting the non-linearity of the subsidence; the dashed line shows the jump at the start of the time series. CSK data is shown in red, TSX descending in blue and TSX ascending in light blue

the period (Fig. 6), with no evidence for pauses in the subsidence or any recharge over the observation period.

We can estimate the total post-eruptive volume loss, $\Delta V_{t}$, at the Nabro magma chamber in such a model by assuming that the subsidence has an initial rapid drop, $\Delta V_{0}$, then continues to decay exponentially, reaching a final volume of $\Delta V_{\infty}$. The total post-eruptive change in volume loss at the chamber is then

$$
\Delta V(t)=\Delta V_{0}+\left(\Delta V_{\infty}-\Delta V_{0}\right)\left(1-\mathrm{e}^{\frac{-t}{t_{R}}}\right)
$$

We use the InSAR-derived time series of source contraction, $\Delta V_{t}$, and find best-fit model with $\Delta V_{0}=$ $0.013 \pm 0.01 \mathrm{~km}^{3}, \Delta V_{\infty}=0.13 \pm 0.01 \mathrm{~km}^{3}$ and a relaxation time of $2.23 \pm 0.15$ years.

\section{Discussion}

In this section, we discuss possible mechanisms for the observed subsidence. Continued post-eruptive subsidence is rare compared to post-eruptive uplift (e.g. Moran 1994; Nakada et al. 1999; Ruiz et al. 2007; Pagli et al. 2012; Girona et al. 2014). Potential processes that could account for post-eruptive subsidence include viscoelastic relaxation (e.g. Newman et al. 2001) cooling and contraction of a magma reservoir (e.g. Poland et al. 2006; Parker et al. 2014) or other mechanisms operating on a closed magmatic system. Alternatively, the subsidence could be caused by the removal of magma or gas from the chamber (e.g. Girona et al. 2014). The smooth, slowly decaying subsidence we observe at Nabro suggests a simple physical process. We explore possible options and attempt to distinguish between the various possible explanations below. We consider each independently, although a combination of processes may be occurring.

\section{Viscoelastic relaxation}

Viscoelastic stress relaxation is sometimes invoked to explain exponentially time-varying deformation (e.g. Newman et al. 2001; Del Negro et al. 2009; Nooner and Chadwick 2009; Parks et al. 2014; Segall 2016; Yamasaki et al. 2017).

In one class of viscoelastic models, the magma chamber sits on the boundary between a hot substrate that behaves viscoelastically and a colder upper elastic layer (Nooner and Chadwick 2009; Yamasaki et al. 2017). In the instance of an eruption (or other volume change at the source), such a system behaves identically to a model in which the magma chamber is embedded in an elastic half space, i.e. a volume loss by eruption will result in subsidence of the surface above the chamber. In the period following a volume change at the chamber, however, the substrate can flow, allowing the elastic stresses in the upper layer to fully relax and the surface to return to its initial state, i.e. if the surface subsided during an eruption, it will slowly uplift during the post-eruptive relaxation period (Nooner and Chadwick 2009). Such a model configuration cannot explain our observations at Nabro, where we observe ongoing subsidence following the eruption.

An alternative viscoelastic model configuration is one where the magma chamber is surrounded by a viscoelastic shell (Dragoni and Magnanensi 1989; Segall 2010, 2016). Thermal models suggest that partially molten material with elastic dilatational and Maxwell viscoelastic deviatoric properties surround magma chambers (e.g. Hodge 1974; Spera 1980; Dingwell and Webb 1989). In such models, a viscoelastic shell is formed as hot magma causes the temperature of the crustal rocks surrounding the chamber to be raised above the brittle-ductile transition (Del Negro et al. 2009). The thickness of the shell is dependent on the size of the magma chamber, the temperature of the magma and the surrounding rock and the composition of the material surrounding the chamber.

Assuming the geometry presented in Segall (2010), which comprises a small spherical magma chamber, with radius $R_{1}$ less than depth $d$, surrounded by a viscoelastic shell out to radius $R_{2}$, embedded in an elastic halfspace, Newman et al. (2001) and Segall (2010) showed that a pressure change, $\Delta P$, would induce vertical surface displacements above the chamber that decay exponentially with time. However, this model requires a mechanism for the pressure change to be maintained. Segall (2016) showed that if there is no flux of material in or out of the chamber, then the co-eruptive pressure change can only 
be maintained if the magma is highly compressible. For an incompressible magma, relaxation of the viscoelastic shell following an eruption would actually cause the effective chamber radius $R_{2}$ to increase, thereby causing uplift. The full, complex behaviour of this model is explored in full in Segall (2016), and the definitions of magma compressibility are given in Rivalta and Segall (2008). The ratio of displacement at infinite time to the initial coeruptive displacement is a function of the ratio of the radii $R_{1} / R_{2}$, the dimensionless ratio, $\mathcal{B}$, of magma and chamber compressibilities ( $\beta_{m}$ and $\beta_{c}$ ) and the Poisson's ratio $v$ :

$$
\frac{u(t \rightarrow \infty)}{u(t=0)}=\frac{\left(R_{2} / R_{1}\right)^{3}}{1+\frac{3(1-v)}{(1+v)} \mathcal{B}\left[\left(\frac{R_{2}}{R_{1}}\right)^{3}-1\right]}
$$

where

$$
\mathcal{B}=\frac{\beta_{c}}{\beta_{m}+\beta_{c}},
$$

which is equal to the ratio between the instantaneous volume reduction of the magma chamber during eruption and the dense rock equivalent of the total volume of erupted material (the inverse of the volume ratio $r_{v}$ defined in Rivalta and Segall 2008). For a Possion's ratio of 0.25 and $\mathcal{B}$ equal to $5 / 9, \frac{u(t \rightarrow \infty)}{u(t=0)}=1$, i.e. we don't expect any deformation from relaxation of the viscoleastic shell if $\mathcal{B}$ is equal to $5 / 9$. If $5 / 9<\mathcal{B} \leq 1$, then viscoelastic relaxation of the shell will cause post-eruptive uplift. If $0 \leq \mathcal{B}<$ $5 / 9$, then we instead expect subsidence. The time history of the surface deformation follows the function of Eq. 1.

For the case of Nabro, Goitom et al. (2015) estimated the total volume of erupted material to be $\sim 0.47 \mathrm{~km}^{3}$ and the co-eruptive contraction of the magma chamber to be in the range 0.07 to $0.1 \mathrm{~km}^{3}$, giving a value of $\mathcal{B}$ of $\sim 0.15$ to 0.21 (i.e. a magma that is highly compressible). We can obtain an independent estimate for $\mathcal{B}$ using the magma properties calculated from thermodynamic modelling (see "Outgassing" section for details). Our calculations give an estimate for $\beta_{m}$ of $6 \times 10^{-11} \mathrm{~Pa}^{-1}$. For an ellipsoidal magma chamber, Rivalta and Segall (2008) showed that $\beta_{c}=3 /(4 \mu)$, so $\beta_{c} \approx 2.5 \times 10^{-11}$. This gives an independent estimate of $\mathcal{B}$ of $\sim 0.29$. Both of these estimates are significantly less than the threshold of $5 / 9$, so viscoelastic relaxation of a spherical shell surrounding the magma chamber is a plausible mechanism for the observed post-eruptive subsidence at Nabro.

In the viscoelastic shell model, the relaxation time constant is a function of the ratio of radii and the viscosity $\eta$ and shear modulus $\mu$ of the shell:

$$
t_{R}=\frac{3 \eta(1-v)}{\mu(1+v)}\left(\frac{R_{2}}{R_{1}}\right)^{3}
$$

We therefore cannot uniquely determine viscosity with this model. For a shear modulus of $10^{10} \mathrm{~Pa}$ and a Poisson's ratio of 0.25 , we obtain viscosities of $\sim 3 \times 10^{17} \mathrm{~Pa} \mathrm{~s}$, $\sim 1 \times 10^{17} \mathrm{~Pa} \mathrm{~s}, \sim 5 \times 10^{16} \mathrm{~Pa} \mathrm{~s}$ and $\sim 1 \times 10^{16} \mathrm{~Pa} \mathrm{~s}$, for values of $R_{2} / R_{1}$ of 1.1, 1.5, 2 and 3, respectively. Our best-fit viscoelastic model is shown in Fig. 7.

The viscosities we derive in this study are similar to those estimated from the viscoelastic models. Del Negro et al. (2009) use a finite element method (FEM) to model ground deformation above a viscoelastic medium and found that viscosities between $10^{13}$ and $10^{17} \mathrm{~Pa} \mathrm{~s}$ exist when the magma chamber wall reaches a temperature of 1500 K. Masterlark et al. (2010) and Newman et al. (2001) found that viscoelastic shell models with viscosities of

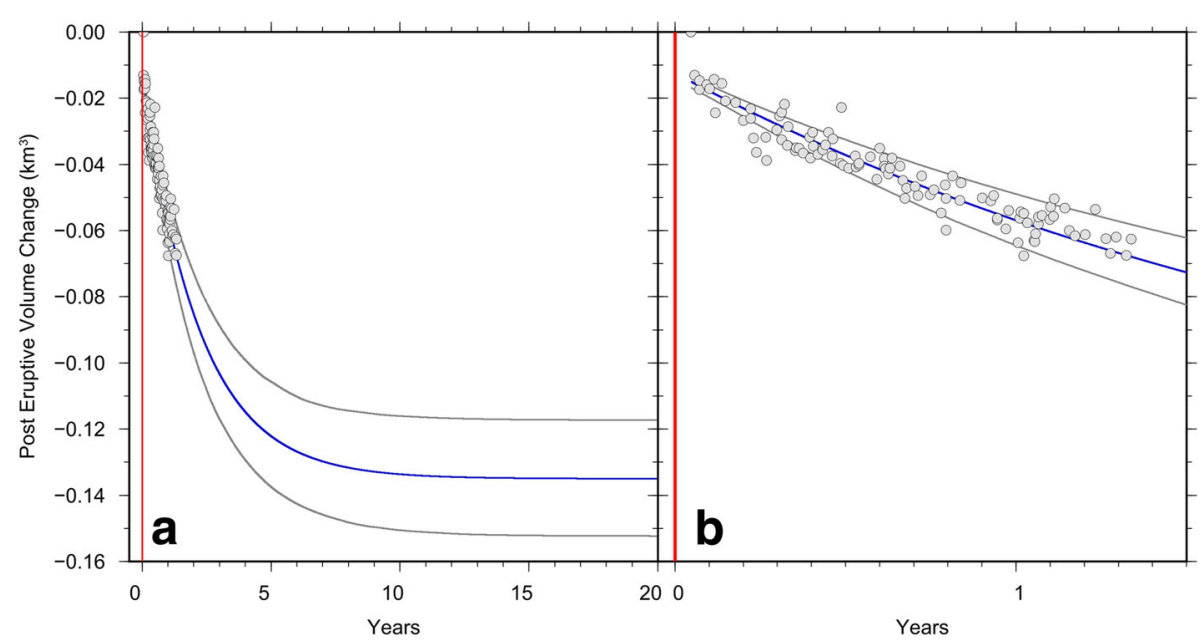

Fig. 7 Best-fit viscoelastic model (blue line) based on grid search for $\Delta V_{\infty}$ and $t_{R}$. Fitted volume change at infinite time $\left(\Delta V_{\infty}\right)$ is $0.13 \pm 0.01 \mathrm{~km}^{3}$, relaxation time $t_{R}=2.23 \pm 0.15$ years. Relative to the start of the eruption (red line). Plotted with all observed data points (grey circles). The grey lines mark the upper and lower one sigma error bounds on the $t_{R}$ and $\Delta V_{\infty}$ values calculated from a Monte Carlo analysis using 1000 simulations. a Viscoelastic model over a period of 20 years. b Model fit over the observation period 
$7.5 \times 10^{16}$ and $10^{16}$ Pa s can explain the surface deformation at Okmok volcano in the Aleutians and Long Valley Caldera, California.

\section{Thermal contraction}

Observations of long-lived subsidence of the ground surface have been attributed to cooling and crystallising (hence contracting) magma at numerous volcanoes across the world, such as Medicine Lake Volcano, California (Poland et al. 2006); Okmok, Aleutians (Caricchi et al. 2014); Askja, Iceland; Basiluzzo island; Aeolian Islands (Tallarico et al. 2003); and Volcan Alcedo, Galapagos (Hooper et al. 2007). The subsidence measured in these studies is thought to have persisted for years to centuries, although the geodetic record typically only captures the most recent subsidence.

Tallarico et al. (2003) proposed a simplified first order model of the volume change induced by a cooling spherical magma chamber. The model accounts for internal magma chamber processes, such as thermal convection and its interaction with crystallisation and chemical differentiation, by allowing the radius of the chamber to change over time. The model requires an open system as volatiles produced by crystallisation (which could theoretically re-pressurise the chamber) are not accounted for and therefore are effectively outgassed. Tallarico et al. (2003) derive an expression for the volume of contraction $\left(\Delta V^{\prime}(t)\right)$ after time $t$ since the beginning of cooling:

$$
\Delta V^{\prime}(t)=-\frac{4}{3} \pi \frac{\Delta \rho}{\rho_{s}}\left(\frac{t^{\frac{3}{2}}}{\Lambda^{3}}-3 R_{0} \frac{t}{\Lambda^{2}}+3 R_{0}^{2} \frac{\sqrt{t}}{\Lambda}\right),
$$

where $R_{0}$ is the starting radius before contraction, $\rho_{s}$ is the density of solid magma, $\Delta \rho$ is density difference between the solid and liquid magma $\left(\rho_{l}\right)$ and $\Lambda$ is a dimensionless parameter that describes the state of heat within the magma chamber and the efficiency of cooling. $\Lambda$ is defined in turn as follows:

$$
\Lambda=\frac{\rho_{l} \sqrt{\pi \chi}\left(C_{p} \Delta T+f Q_{l}\right)}{2 k T_{s}},
$$

where $C_{p}$ is the specific heat capacity, $\Delta T$ is the temperature change, $\chi$ is the thermal diffusivity of the crust, $f$ is the percentage of magma within the chamber that crystallises, $Q_{l}$ is the latent heat of crystallisation, $k$ is the thermal conductivity of the crust and $T_{S}$ is the temperature of the boundary through which the heat is passing. The temperature decrease induces the growth of crystals and contraction of the magma body (for full technical details, see Tallarico et al. (2003)).

To find an appropriate value of $\Lambda$, we varied the values for the constituent parameters discussed above based on the values used in previous studies that are most appropriate to Nabro (Table 1). Using these values, we calculated a maximum and minimum $\Lambda$, then we inverted for the best fitting $\Delta V^{\prime}$ over the observed time period by performing a grid search for the value of $R_{0}$ that best fits our InSARderived volume change time series model in (1). Smaller radii of the chamber would lead to implausible values of $\Lambda$ and have therefore been ruled out.

The maximum plausible value of $\Lambda$ is 1095 (Table 1). This requires an initial radius of $2.39 \pm 0.005 \mathrm{~km}$ to fit the subsidence data; the minimum likely value of $\Lambda$ of 191 implies an initial radius of $0.95 \pm 0.002 \mathrm{~km}$. Both models fit the contraction histories well (Fig. 8). The model with the smaller initial radius reaches the equilibrium such that contraction ceases at approximately 1000 years from the eruption date, whereas for the larger body, this equilibrium is reached after approximately 10,000 years. The model implies that the cooling magma body has a volume in the range of $\sim 3.5$ to $\sim 60 \mathrm{~km}^{3}$.

The simple cooling model requires a large magma body to be present beneath Nabro, with a volume that is 35 to 600 times larger than the volume change that occurred during this eruption. Therefore, most of the magma would have been present prior to the eruption. If the model is valid, we would expect pre-eruption geodetic observations to also show subsidence at Nabro or to see evidence for the injection of a large magma body immediately before the eruption. Pagli et al. (2014) obtained a time series of cumulative displacement between October 2006 and July 2010 over the entire Afar Region. They did not observe any surface displacements at Nabro during this period. Therefore, for thermal contraction to be a plausible mechanism for observations at Nabro, we would require a very large injection of new material into the chamber between July 2010 and the eruption on 12 June 2011. Unfortunately, there was no radar data acquired in this period over Nabro. Regional seismicity data shows that there was a $M_{\mathrm{W}} 4.5$ earthquake on 31 March 2011 (Goitom et al. 2015), implying that some magma movement took place. Donovan et al. (2018) performed whole rock and melt inclusion analysis on the samples taken from Nabro and the surrounding region during a field expedition in October 2011. Their petrological observations show that new magma arrived in a pre-existing chamber, likely triggering the eruption. But the new magma volume is likely to be small compared to the size of the pre-existing chamber. Further, we also note that for a radius between 1 and $2 \mathrm{~km}$ and a volume of contraction of $0.06 \mathrm{~km}^{3}$, the resulting stress change is very large. This suggests that this mechanism alone is not controlling the subsidence observed at Nabro.

An alternative cooling model that could apply was suggested by Tomiya and Takahashi (1995). They proposed that the stirring of a thermally stratified magmatic system could lead to accelerated cooling and contraction. This model is hard to rule out using the deformation data without independent constraints. 
Table 1 Example minimum and maximum values for the thermal characteristics of a magma chamber used to calculate thermal contraction

\begin{tabular}{llllll}
\hline Param. & Units & Max value & Reference & Min value & Reference \\
\hline$C_{p}$ & $\mathrm{~J} \mathrm{~kg}^{-1} \mathrm{~K}^{-1}$ & 1100 & Martin et al. (1987) & 1047 & Armienti et al. (1984) \\
$f$ & & 0.9 & Tallarico et al. (2003) & 0.6 & Armienti et al. (1984) \\
$k$ & $\mathrm{~W} \mathrm{~m}^{-1} \mathrm{~K}^{-1}$ & 3 & Chapman (1986) & 2.3 & Armienti et al. (1984) \\
$Q_{l}$ & $\mathrm{~J} \mathrm{Kg}^{-1}$ & 800000 & Armienti et al. (1984) & 334944 & Tallarico et al. (2003) \\
$T_{S}$ & $\mathrm{~K}$ & 1130 & Donovan et al. (2018) & 1030 & Donovan et al. (2018) \\
$\Delta T$ & $\mathrm{~K}$ & 350 & Armienti et al. (1984) & 150 & Huppert and Sparks (1981) \\
$\rho_{S}$ & $\mathrm{~kg} \mathrm{~m}^{-3}$ & 3300 & Scandone and Giacomelli (1998) & 3084 & Scandone and Giacomelli (1998) \\
$\rho_{l}$ & $\mathrm{~kg} \mathrm{~m}^{-3}$ & 2750 & Sparks and Huppert (1984) & 2570 & Armienti et al. (1984) \\
\hline
\end{tabular}

\section{Magma withdrawal}

Subsidence in some instances has been attributed to volume loss following the outflow of hydrothermal fluids or drainage of magma. The magma chamber beneath Askja volcano has been losing volume since at least 1983 (Pagli et al. 2006); this has been interpreted as a combination of magma drainage and thermal contraction (de Zeeuw-van Dalfsen et al. 2005). Hamlyn et al. (2014) suggest potential linkages between the shallow chamber at Nabro and deeper potential sources based on the distribution of seismic data. If magma drainage is occurring beneath Nabro, it must be flowing to a depth where the resultant deformation cannot be detected at the surface. We have modelled a Mogi geometry within an elastic halfspace, which undergoes a volume decrease of $0.13 \mathrm{~km}^{3}$. We found that if this source is located at a depth of $30 \mathrm{~km}$, the resulting surface displacement is approximately $3 \mathrm{~mm}$, which is less than the level of noise in our atmosphere-corrected InSAR data. Therefore, based on this model, $30 \mathrm{~km}$ represents an upper bound on the detectable depth of magma movement. If this mechanism is applicable, then we believe it would be more likely that the magma was draining into a hot, inelastic part of the lower crust or upper mantle, but a physical mechanism for this is not obvious.

\section{Outgassing}

An alternative mechanism for post-eruptive volume loss is gas loss from the magma chamber. Outgassing has previously been invoked as the mechanism forcing the continued subsidence of Llaima volcano (Chile) and Satsuma-Iwojima volcano (Japan) (Girona et al. 2014; Iguchi et al. 2002). The eruption of Nabro was notable for its significant output of $\mathrm{SO}_{2}$, an estimated $4.3 \mathrm{Tg}$ of which was emitted to the atmosphere during the eruption (Theys et al. 2013), one of the largest atmospheric aerosol pertubations since the 1991 eruption of Mt. Pinatubo. We consider the mass of $\mathrm{SO}_{2}$ calculated by Theys et al. (2013) to be a maximum value; Sealing et al. (2015) estimated the emitted atmospheric $\mathrm{SO}_{2}$ to be $2.3 \mathrm{Tg}$.

We have generated a suite of gas compositions for a magma in the system C-S-O-H-Fe during decompression, using thermodynamic modelling software D-Compress
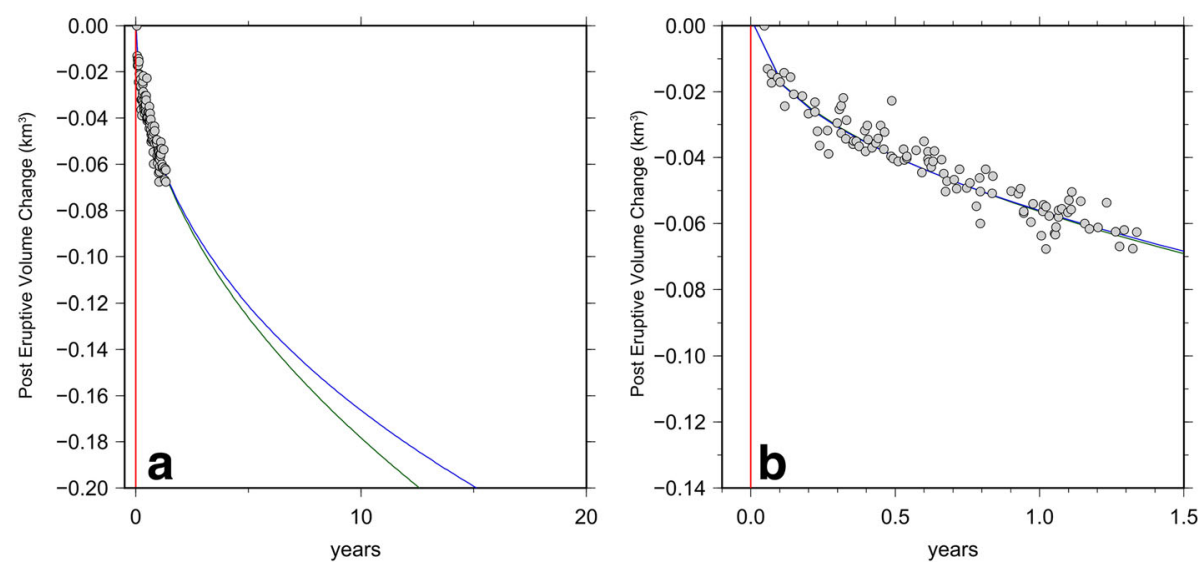

Fig. 8 The volume of thermal contraction calculated from the maximum value of $\Lambda$ is shown in blue, and the volume of contraction assuming a minimum is shown in green. Using $\Lambda_{\text {min }}$ requires an initial starting radius of $0.944 \mathrm{~km}$, and $\Lambda_{\text {max }}$ results in an initial radius of $2.386 \mathrm{~km}$. a Thermal model over a period of 20 years. b Model fit over the observation period 
(Burgisser et al. 2015). Across an appropriate range (10-1000 MPa) of crustal pressures, we calculate the amount and composition of exsolved gas and consequent bulk magma density (similar to the approach adopted in McCormick Kilbride et al. (2016)). The model outputs can be used to calculate co-eruptive volume change and $\mathrm{SO}_{2}$ emissions, which we compared to the observed co-eruptive InSAR-derived volume change and $\mathrm{SO}_{2}$ emissions reported by Goitom et al. (2015) and Theys et al. (2013), respectively. By fitting these observations, we can reconstruct pre-eruptive storage conditions.

We assume that the final volume loss predicted by the exponential decay model $\left(\Delta V_{\infty}=0.13 \mathrm{~km}^{3}\right)$ is instead explained by gas loss from the magma chamber. Our calculations suggest a gas-rich magma with $\sim 10 \%$ by volume exsolved gas at a depth of $6.4 \mathrm{~km}$, equivalent to $\sim 2$ weight percent gas, composed mainly of carbon and sulphur, which is broadly consistent with the melt inclusion data of Donovan and Pyle (2017). If we assume that the entire post-eruptive subsidence volume loss $\left(\Delta V_{\infty}\right)$ of $0.13 \mathrm{~km}^{3}$ is a consequence of this gas phase escaping to the surface, then we obtain a minimum size of the magma chamber of $1.3 \mathrm{~km}^{3}$ for the case when all of this gas escapes following the eruption. If this gas is a pure $\mathrm{CO}_{2}$ phase at $6.4 \mathrm{~km}$ depth, the total mass of $\mathrm{CO}_{2}$ leaving the chamber would be $\sim 90 \mathrm{Mt}$, using the ideal gas law, which is equivalent to a flux of $24 \mathrm{kt}^{-1} \mathrm{~d}^{-1}$ if it is emitted evenly over 10 years.

Note that this is the rate of $\mathrm{CO}_{2}$ leaving the chamber and not necessarily the flux that would be measured at the vent area. There is likely to be a diffuse flux of $\mathrm{CO}_{2}$ on and around the flanks of the volcano controlled by fractures and other more highly permeable areas. At Hekla volcano, comparison of the $\mathrm{CO}_{2}$ content of ground water to the $\mathrm{CO}_{2}$ content of volcanic plumes suggests that as much as 94 to $99 \%$ of the total $\mathrm{CO}_{2}$ from the volcano is removed by hydrothermal systems. Nabro was assessed for potential development as a hydrothermal energy source by the Eritrean government; the report suggests a 'potentially significant' hydrothermal system beneath the volcano. This implies that some reduction of the $\mathrm{CO}_{2}$ flux to the atmosphere may be possible, but we cannot quantify this. Additionally, this $\mathrm{CO}_{2}$ flux is a maximum estimate as the model assumes that the magma is instantaneously emplaced at a certain depth, and this determines the resulting composition and fluid volume fractions; the model does not simulate the exsolution of $\mathrm{CO}_{2}$ as the magma migrates from depth to the storage zone prior to the eruption. It also assumes that no outgassing occurs at Nabro prior to the eruption.

Nevertheless, outgassing is a plausible mechanism to explain some or all of the subsidence observed at Nabro following eruption. To explain the observations, at least $1.3 \mathrm{~km}^{3}$ of melt with no prior gas loss would have to be present in the crust, and it would have to lose its entire gas content following the eruption, for example, through fracture systems created during the numerous earthquakes that occurred. For gas loss to be a plausible mechanism, we would expect a much larger magma body than the minimum bound from this calculation, as some gas will have likely been lost prior to eruption, and some gas may not escape.

\section{Conclusions}

Nabro volcano is situated in an arid environment with a lower and broader topographic profile than many other stratovolcanoes, but despite these factors, we still find significant atmospheric signals within our InSAR data. We have found that applying an empirical correction to the CSK data in order to remove atmospheric signals significantly underestimates the rate of subsidence due to the correlation between the signal and the topography of the volcanic edifice. Using auxiliary weather model outputs from ERA-I to correct the InSAR data is a necessary step to adequately remove atmospheric artefacts without removing the topographically correlated volcanic signal.

By undertaking kinematic modelling of the InSAR time series, we were able to observe how the plumbing system evolved following the eruption. Beneath Nabro, we find no time-dependent changes in the 3D position of the source of the deformation. This is consistent with the post-eruptive processes at the magma chamber being responsible for the subsidence.

To explain the subsidence, we explored closed-system processes (viscoelastic relaxation, thermal contraction) and processes that involve the loss of material (magma, gas) from the chamber. We consider thermal contraction an unlikely mechanism because no subsidence was observed prior to the eruption. Viscoelastic relaxation of a shell surrounding the chamber can explain the observations-it requires a magma compressibility that is consistent with estimates from the ratio of erupted volume to co-eruptive volume change at the magma chamber.

Although they cannot be ruled out, processes that lose magma directly seem unlikely as they would require a mechanism for deep emplacement of magma (drainback) from the chamber. Outgassing is a plausible mechanism to explain some or all of the subsidence. $\mathrm{CO}_{2}$ is the primary gas phase at the depth of the magma chamber-for loss of this gas phase to explain all the post-eruptive subsidence requires a minimum magma chamber size of $1.3 \mathrm{~km}^{3}$. It is also possible that a combination of these processes contributes to the overall subsidence observed, such as both viscoelastic relaxation and outgassing occurring beneath Nabro.

A future reversal of the subsidence at Nabro will have important implications for potential future eruptions. 
Future uplift of the edifice would suggest that a new influx magma is repressurising the system. However, it is possible that such recharge would be masked by the ongoing subsidence.

Our study emphasises the value of long geodetic time series at volcanic centres. Observations of pre-, co- and post-eruptive deformation provide powerful constraints on possible mechanisms working in the magma system. However, to fully understand a magmatic plumbing system and the physical mechanisms at work, we require observations and data from other sources. In particular, petrological data, direct monitoring of gas emissions and gravity and seismic monitoring would all be extremely valuable in future studies.

\section{Additional file}

Additional file 1: The RMS difference in metres between the LOS displacement predicted by a Mogi source model for each epoch. Different satellites are shown with different colours. (JPG 204 kb)

\section{Abbreviations}

CSK: COSMO-SkyMed (Constellation Of Small Satellites for Mediterranean Basin Observation); InSAR: Interferometric synthetic aperture RADAR; LOS:

Line-of-sight; MER: Main Ethiopian Rift; SBAS: Small baseline subset approach; SRTM: Shuttle RADAR topography mission; TSX: TerraSAR-X

\section{Acknowledgements}

We would like to thank the Southern Red Sea Region Administration, Eritrea, for the support with the seismic deployments. Funding was provided by NERC grant NE/J012297/1. Figures were produced using Generic Mapping Tools (GMT) (Wessel and Smith 1998). JEH was funded through a NERC studentship at the University of Leeds. TerraSAR-X data were provided under proposal GEO1206. Raw RADAR data can be obtained by proposal from DLR using the website http://sss.terrasar-x.dlr.de/. COSMO-SkyMed data were processed at IREA-CNR within the Italian Space Agency (ASI) SAR4Volcanoes project (agreement 1/034/11/0). We also thank Simona Zoffoli of ASI for her support in planning and providing COSMO-SkyMed data. COMET is the NERC Centre for the Observation and Modelling of Earthquakes, Volcanoes and Tectonics.

\section{Funding}

Funding was provided by NERC grant NE/J012297/1. JEH was funded through a NERC studentship at the University of Leeds. TerraSAR-X data were provided under proposal GEO1206. COSMO-SkyMed data were provided by the Italian Space Agency (ASI) under the SAR4Volcanoes project (agreement I/034/11/0).

\section{Authors' contributions}

JEH conceived and completed the study as part of their Ph.D. TJW assisted the processing, modelling and completion of the manuscript. RJW assisted with the atmospheric correction applied to the InSAR data. CP assisted with the processing of the InSAR data. ES, SP and FC processed the Cosmo-SkyMed data. BM and ME investigated the effect of degassing. DK and JN advised on the project. CO is the PI for the project. All authors read and approved the final manuscript.

\section{Competing interests}

The authors declare that they have no competing interests.

\section{Publisher's Note}

Springer Nature remains neutral with regard to jurisdictional claims in published maps and institutional affiliations.

\section{Author details}

${ }^{1}$ TerraDat, 1 Link Trade Park, Cardiff CF11 8TQ, UK. ${ }^{2}$ COMET, School of Earth and Environment, University of Leeds, Leeds LS2 9JT, UK. ${ }^{3}$ Department of Earth
Sciences, Durham University, Durham DH1 3LE, UK. ${ }^{4}$ Dipartimento di Scienze della Terra, Università di Pisa, 56126 Pisa, Italy. ${ }^{5}$ Istituto per il rilevamento elettromagnetico dell'ambiente - National Research Council (IREA-CNR), 80124 Naples, Italy. ${ }^{6}$ Department of Earth Sciences, University of Cambridge, Cambridge CB2 3EQ, UK. ${ }^{7}$ National Oceanography Centre Southampton, University of Southampton, Southampton SO14 3ZH, UK. ${ }^{8}$ Università degli Studi di Firenze, Firenze 50121, Italy. ${ }^{9}$ Department of Geography, University of Cambridge, Cambridge CB2 3EQ, UK.

Received: 6 December 2017 Accepted: 25 April 2018

Published online: 07 June 2018

\section{References}

Armienti P, Barberi F, Innocenti F (1984) A model of the phlegraean fields magma chamber in the last 10,500 years. Bull Volcanol 47(2):349-358

Bathke H, Shirzaei M, Walter T (2011) Inflation and deflation at the steep-sided Ilaima stratovolcano (chile) detected by using InSAR. Geophys Res Lett 38(10). https://doi.org/10.1029/2011GL047168

Beauducel F, Briole P, Froger J-L (2000) Volcano-wide fringes in ers synthetic aperture radar interferograms of etna (1992-1998): Deformation or tropospheric effect? J Geophys Res Solid Earth 105(B7):16391-16402

Bekaert D, Hooper A, Wright T (2015) A spatially variable power law tropospheric correction technique for InSAR data. J Geophys Res Solid Earth 120(2):1345-1356

Berardino P, Fornaro G, Lanari R, Sansosti E (2002) A new algorithm for surface deformation monitoring based on small baseline differential sar interferograms. IEEE Trans Geosci Remote Sens 40(11):2375-2383

Biggs J, Wright T, Lu Z, Parsons B (2007) Multi-interferogram method for measuring interseismic deformation: Denali Fault, Alaska. Geophys J Int 170(3):1165-1179

Bluth GJ, Doiron D, Schnetzler CC, Krueger AJ, Walter LS (1992) Global tracking of the SO2 clouds from the June, 1991, Mount Pinatubo eruptions. Geophys Res Lett 19(2):151-154

Bürgmann R, Rosen PA, Fielding EJ (2000) Synthetic aperture radar interferometry to measure earth's surface topography and its deformation. Ann Rev Earth Planet Sci 28(1):169-209

Burgisser A, Alletti M, Scaillet B (2015) Simulating the behavior of volatiles belonging to the $\mathrm{C}-\mathrm{O}-\mathrm{H}-\mathrm{S}$ system in silicate melts under magmatic conditions with the software D-compress. Comput Geosci 79:1-14

Caricchi L, Biggs J, Annen C, Ebmeier S (2014) The influence of cooling, crystallisation and re-melting on the interpretation of geodetic signals in volcanic systems. Earth Planetary Sci Lett 388:166-74

Chapman D (1986) Thermal gradients in the continental crust. Geol Soc London Special Publ 24(1):63-70

Covello F, Battazza F, Coletta A, Lopinto E, Fiorentino C, Pietranera L, Valentini G, Zoffoli S (2010) COSMO-SkyMed an existing opportunity for observing the earth. J Geodyn 49(3):171-180

de Zeeuw-van Dalfsen E, Rymer H, Sigmundsson F, Sturkell E (2005) Net gravity decrease at Askja volcano, Iceland: constraints on processes responsible for continuous caldera deflation, 1988-2003. J Volcanol Geotherm Res 139(3):227-239

Dee DP, Uppala S, Simmons A, Berrisford P, Poli P, Kobayashi S, Andrae U, Balmaseda M, Balsamo G, Bauer P, et al. (2011) The era-interim reanalysis: configuration and performance of the data assimilation system. Q J R Meteorol Soc 137(656):553-597

Del Negro C, Currenti G, Scandura D (2009) Temperature-dependent viscoelastic modeling of ground deformation: application to etna volcano during the 1993-1997 inflation period. Phys Earth Planet Inter 172(3):299-309

Dingwell DB, Webb SL (1989) Structural relaxation in silicate melts and non-newtonian melt rheology in geologic processes. Phys Chem Miner 16(5):508-516

Donovan A, Blundy J, Oppenheimer C, Buisman I (2018) The 2011 eruption of Nabro volcano, Eritrea: perspectives on magmatic processes from melt inclusions. Contrib Mineral Petrol 173(1):1

Dragoni M, Magnanensi C (1989) Displacement and stress produced by a pressurized, spherical magma chamber, surrounded by a viscoelastic shell. Phys Earth Planet Inter 56(3-4):316-328

Ebmeier S, Biggs J, Mather T, Amelung F (2013) Applicability of InSAR to tropical volcanoes: insights from Central America. Geol Soc London Special Publ 380(1):15-37 
Elliott J, Biggs J, Parsons B, Wright T (2008) InSAR slip rate determination on the Altyn Tagh fault, northern Tibet, in the presence of topographically correlated atmospheric delays. Geophys Res Lett 35(12). https://doi.org/10. 1029/2008GL033659

Ferretti A, Prati C, Rocca F (2001) Permanent scatterers in SAR interferometry. IEEE Trans Geosci Remote Sens 39(1):8-20

Fournier T, Pritchard M, Riddick S (2010) Duration, magnitude, and frequency of subaerial volcano deformation events: new results from latin america using InSAR and a global synthesis. Geochem Geophys Geosyst 11(1) https://doi.org/10.1029/2009GC002558

Girona T, Costa F, Newhall C, Taisne B (2014) On depressurization of volcanic magma reservoirs by passive degassing. J Geophys Res Solid Earth 119(12):8667-8687

Goitom B, Oppenheimer C, Hammond JO, Grandin R, Barnie T, Donovan A, Ogubazghi G, Yohannes E, Kibrom G, Kendall J-M, et al. (2015) First recorded eruption of Nabro volcano, Eritrea, 2011. Bull Volcanol 77(10):85

Grandin R, Socquet A, Doin M-P, Jacques E, de Chabalier J-B, King G (2010) Transient rift opening in response to multiple dike injections in the Manda Hararo rift (Afar, Ethiopia) imaged by time-dependent elastic inversion of interferometric synthetic aperture radar data. J Geophys Res Solid Earth 115(B9). https://doi.org/10.1029/2009JB006883

Hamlyn JE, Keir D, Wright TJ, Neuberg JW, Goitom B, Hammond JO, Pagli C, Oppenheimer C, Kendall J, Grandin R, et al. (2014) Seismicity and subsidence following the 2011 Nabro eruption, Eritrea: insights into the plumbing system of an off-rift volcano. J Geophys Res Solid Earth 119(11):8267-8282

Hodge DS (1974) Thermal model for origin of granitic batholiths. Nature 251(5473):297-299

Hooper A, Segall P, Zebker H (2007) Persistent scatterer interferometric synthetic aperture radar for crustal deformation analysis, with application to Volcán Alcedo, Galápagos. J Geophys Res Solid Earth 112(B7). https:// doi.org/10.1029/2006JB004763

Hooper A, Bekaert D, Spaans K, Arıkan M (2012) Recent advances in SAR interferometry time series analysis for measuring crustal deformation. Tectonophysics 514:1-13

Huppert HE, Sparks RSJ (1981) The fluid dynamics of a basaltic magma chamber replenished by influx of hot, dense ultrabasic magma. Contributions to Mineralogy and Petrology 75(3):279-289

Iguchi M, Saito E, Nishi Y, Tameguri T (2002) Evaluation of recent activity at Satsuma-Iwojima-Felt earthquake on June 8, 1996. Earth Planets Space 54(3):187-195

Jolivet R, Grandin R, Lasserre C, Doin M-P, Peltzer G (2011) Systematic InSAR tropospheric phase delay corrections from global meteorological reanalysis data. Geophys Res Lett 38(17). https://doi.org/10.1029/ 2011 GL048757

Kilbride BM, Edmonds M, Biggs J (2016) Observing eruptions of gas-rich compressible magmas from space. Nat Commun 7:13744

Kiyoo MOGI (1958) Relations between the eruptions of various volcanoes and the deformations of the ground surfaces around them. Earthq Res Inst 36:99-134

Lu Z, Dzurisin D, Biggs J, Wicks C, McNutt S (2010) Ground surface deformation patterns, magma supply, and magma storage at Okmok volcano, Alaska, from InSAR analysis: 1. intereruption deformation, 1997-2008. J Geophys Res Solid Earth 115(B5). https://doi.org/10.1029/2009JB006969

Martin D, Griffiths RW, Campbell IH (1987) Compositional and thermal convection in magma chambers. Contrib Mineral Petrol 96(4):465-475

Massonnet D, Feigl KL (1998) Radar interferometry and its application to changes in the earth's surface. Rev Geophys 36(4):441-500

Masterlark T, Haney M, Dickinson H, Fournier T, Searcy C (2010) Rheologic and structural controls on the deformation of Okmok volcano, Alaska: Fems, InSAR, and ambient noise tomography. J Geophys Res Solid Earth 115(B2). https://doi.org/10.1029/2009JB006324

Moran SC (1994) Seismicity at Mount St. Helens, 1987-1992: evidence for repressurization of an active magmatic system. J Geophys Res Solid Earth 99(B3):4341-4354

Nakada S, Shimizu H, Ohta K (1999) Overview of the 1990-1995 eruption at Unzen volcano. J Volcanol Geotherm Res 89(1):1-22

Newman A, Dixon TH, Ofoegbu G, Dixon J (2001) Geodetic and seismic constraints on recent activity at Long Valley Caldera, California: evidence for viscoelastic rheology. J Volcanol Geotherm Res 105(3):183-206
Nooner SL, Chadwick WW (2009) Volcanic inflation measured in the caldera of axial seamount: implications for magma supply and future eruptions. Geochem Geophys Geosyst 10(2). https://doi.org/10.1029/2008GC002315

Pagli C, Sigmundsson F, Arnadóttir T, Einarsson P, Sturkell E (2006) Deflation of the Askja volcanic system: constraints on the deformation source from combined inversion of satellite radar interferograms and GPS measurements. J Volcanol Geotherm Res 152(1):97-108

Pagli C, Wright TJ, Ebinger CJ, Yun S-H, Cann JR, Barnie T, Ayele A (2012) Shallow axial magma chamber at the slow-spreading Erta Ale ridge. Nat Geosci 5(4):284-288

Pagli C, Wang H, Wright TJ, Calais E, Lewi E (2014) Current plate boundary deformation of the Afar rift from a 3-D velocity field inversion of InSAR and GPS. J Geophys Res Solid Earth 119(11):8562-8575

Parsons B, Wright T, Rowe P, Andrews J, Jackson J, Walker R, Khatib M, Talebian M, Bergman E, Engdahl E (2006) The 1994 Sefidabeh (Eastern Iran) earthquakes revisited: new evidence from satellite radar interferometry and carbonate dating about the growth of an active fold above a blind thrust fault. Geophys J Int 164(1):202-217

Parker AL, Biggs J, Lu Z (2014) Investigating long-term subsidence at medicine Lake Volcano, CA, using multitemporal InSAR. Geophys J Int 199(2):844-859

Parks MM, Moore JD, Papanikolaou X, Biggs J, Mather TA, Pyle DM, Raptakis C, Paradissis D, Hooper A, Parsons B, et al. (2015) From quiescence to unrest: 20 years of satellite geodetic measurements at Santorini volcano, Greece. J Geophys Res Solid Earth 120(2):1309-1328

Poland M, Bürgmann R, Dzurisin D, Lisowski M, Masterlark T, Owen S, Fink J (2006) Constraints on the mechanism of long-term, steady subsidence at Medicine Lake Volcano, Northern california, from GS, leveling, and InSAR. J Volcanol Geotherm Res 150(1):55-78

Rivalta E, Segall P (2008) Magma compressibility and the missing source for some dike intrusions. Geophys Res Lett 35(4). https://doi.org/10.1029/ 2007GL032521

Rosen PA, Hensley S, Peltzer G, Simons M (2004) Updated repeat orbit interferometry package released. Eos Trans Am Geophys Union 85(5):47

Ruiz A, Geist D, Chadwick W (2007) Inflation of Sierra Negra volcano since the 2005 eruption. In: AGU Fall Meeting Abstracts. http://adsabs.harvard.edu/ abs/2007AGUFM.V53C1422R

Scandone R, Giacomelli L (1998) Vulcanologia: Principi Fisici e Metod D'indagine. Liguori. https://www.ibs.it/vulcanologia-principi-fisici-metodid-libro-roberto-scandone-lisetta-giacomelli/e/9788820726874

Sealing C, Carn S, Harris A (2015) The first historic eruption of Nabro, Eritrea: Insights from thermal and UV satellite data. In: AGU Fall Meeting Abstracts. http://adsabs.harvard.edu/abs/2015AGUFM.V23B3097S

Segall P (2010) Earthquake and volcano deformation. Princeton University Press, Princeton

Segall P (2016) Repressurization following eruption from a magma chamber with a viscoelastic aureole. J Geophys Res Solid Earth 121(12):8501-8522

Sparks RSJ, Huppert HE (1984) Density changes during the fractional crystallization of basaltic magmas: fluid dynamic implications. Contrib Mineral Petrol 85(3):300-309

Spera F (1980) Thermal evolution of plutons: a parameterized approach. Science 207(4428):299-301

Sturkell E, Sigmundsson F (2000) Continuous deflation of the Askja caldera, Iceland, during the 1983-1998 noneruptive period. J Geophys Res Solid Earth 105(B11):25671-25684

Tallarico A, Dragoni M, Anzidei M, Esposito A (2003) Modeling long-term ground deformation due to the cooling of a magma chamber: case of Basiluzzo Island, Aeolian Islands, Italy. J Geophys Res Solid Earth 108(B12). https://doi.org/10.1029/2002JB002376

Theys N, Campion R, Clarisse L, van Gent J, Dils B, Corradini S, Merucci L, Coheur P, Van Roozendael M, Hurtmans D, et al. (2013) Volcanic SO2 fluxes derived from satellite data: a survey using OMI, GOME-2, IASI and MODIS. Atmos Chem Phys (ACP). http://adsabs.harvard.edu/abs/2012ACPD...1231349T

Tomiya A, Takahashi E (1995) Reconstruction of an evolving magma chamber beneath Usu volcano since the 1663 eruption. J Petrol 36(3):617-636

Walters R, Elliott J, Li Z, Parsons B (2013) Rapid strain accumulation on the Ashkabad fault (turkmenistan) from atmosphere-corrected InSAR. J Geophys Res Solid Earth 118(7):3674-3690

Wang H, Wright T, Biggs J (2009) Interseismic slip rate of the northwestern Xianshuihe fault from InSAR data. Geophys Res Lett 36(3). https://doi.org/ 10.1029/2008GL036560 
Wessel P, Smith WHF (1998) New, improved version of Generic Mapping Tools released. EOS Trans Am Geophys Union 79(47):579

Wicks CW, Dzurisin D, Ingebritsen S, Thatcher W, Lu Z, Iverson J (2002)

Magmatic activity beneath the quiescent three sisters volcanic center, Central Oregon Cascade Range, USA. Geophys Res Lett 29(7). https://doi. org/10.1029/2001GL014205

Wright TJ, Ebinger C, Biggs J, Ayele A, Yirgu G, Keir D, Stork A (2006) Magma-maintained rift segmentation at continental rupture in the 2005 Afar dyking episode. Nature 442(7100):291-294

Yamasaki T, Kobayashi T, Wright TJ, Fukahata Y (2017) Viscoelastic crustal deformation by magmatic intrusion: a case study in the Kutcharo caldera, eastern Hokkaido, Japan. J Volcanol Geotherm Res 349:128-145

Zebker HA, Rosen PA, Hensley S (1997) Atmospheric effects in interferometric synthetic aperture radar surface deformation and topographic maps. J Geophys Res olid earth 102(B4):7547-7563

\section{Submit your manuscript to a SpringerOpen ${ }^{\circ}$ journal and benefit from:}

- Convenient online submission

- Rigorous peer review

- Open access: articles freely available online

- High visibility within the field

- Retaining the copyright to your article

Submit your next manuscript at $\gg$ springeropen.com 